\title{
Editorial: The New Normal Life After Lockdown on COVID- 9 Pandemic
}

\author{
Indonesian Nursing Journal of Education and \\ Clinic (INJEC) \\ Volume 5, Issue I, June 2020 \\ injec.aipni-ainec.org/index.php/INJEC/index \\ The Association of Indonesian Nurse \\ Education Center (AINEC) \\ https://injec.aipni- \\ ainec.org/index.php/INJEC/issue/view/I 5/show \\ Toc
}

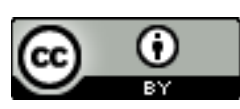

\author{
Dr. Sirikanok Klankhajhon \\ Faculty of Nursing, Naresuan University, Phitsanulok, Thailand \\ email: sirikanok k@hotmail.com
}

The new normal life has become a new way of life including healthcare education, and the most common question is "what will happen to our nursing school or healthcare education after the lockdown?" It challenges healthcare education to improve the quality of the learning process, which consists of professionals, resources, finance and management, rather than work from home and online learning. Students have returned to school for face-face learning as a practicum in the simulation laboratory, hospital and communities. In the short term, organizations should be prepared for a new wave of COVID19 pandemic. The basic principles are screening students and staff for signs and symptoms, cleaning and disinfecting the building and classrooms, promoting social distance of at least I meter, handwashing, and wearing a mask (Bender et al', 2020). In the long term, embedded learning will be researched to develop in healthcare education that consist of face-to-face, online, simulation, and/or selfstudy learning with the new technology such as virtual reality (VR) for nursing practicum ( $\mathrm{Hu}-$ Au \& Lee, 2017; Subedi et al., 2020). This strategy will be constructed to continue healthcare education during the new normal following national and international policies. The information and procedures to prevent and control the COVID-19 pandemic will be improved for effective communication based on the context. The mental health and psychosocial support will be integrated and encouraged in the COVID-19 prevention and control activities to reduce their anxieties and maintain the wellbeing of the students and staff (Bender et al., 2020; Savitsky et al., 2020). In addition, healthcare educators should collaborate and share the teaching and learning knowledge including tacit knowledge. This will be useful to improve effective learning and innovation in healthcare education during this challenging period. 